\title{
Sociolinguistics and the Politics of Helping: Language Use in the Political Mobilization of Low-Income Groups
}

\author{
Trutz von Trotha \\ Institute of Sociology, University of Hannover \\ Richard Harvey Brown \\ Department of Sociology. University of Maryland
}

\begin{abstract}
Intelligible communication between different groups and classes in a society is a precondition for the existence of a 'public in the classical, political sense of that term. The importance of such communication for a democratic policy was highlighted in the sixties when both reformers and revolutionaries generally failed in their efforts to educate or politucize low-income groups. In this essay we discuss sociolinguistic theories as they bear on this question. First, we critically assess theories that bring the methods of linguistics to micro-sociological studies of speech behaviour. Then we relate this work to the rich ethnographic literature on low-income culture, placing this amalgam of linguistics and ethnography in a larger political economic context. We conclude by suggesting some moral and political implications of such a project.
\end{abstract}

Student [Organizer]: I know you have heen deprived and are impatient with the power structure.

Gang Member: Let me tell you something. I have never been denied cause I go out and steal what I want, man, take what I want, man, and I get it, boyt Anything I want in life. I'm going to get. And I'm not going to let no fool tell me. Well. look here. Jack, you can't do this here because it's against the law, and that kind of bullshit. (Krisberg, 1972:69)

One of the more frustrating experiences in the 1960's of both American and European students in their efforts to politicize oppressed groups was the lack of communication between the agitating students and their 'clients'. It appeared that slum dwellers, and especially gang youths. were politically ignorant and disinterested. oblivious to larger societal issues. Spergel, for example (1969), reports that civil rights and Black militant organizations sought to mobilize gang youths politically because of the latter's readiness for direct actions, but the organizers came to realize that gang members were more motivated to enter the system than to subvert it. This was highlighted during riots in American cities where gang participation was not a major factor except to mollify protests (Short 1976). There 
seemed to be no bridges between educated radical groups and gang members. Each appeared to be living in a different society and speaking a different language.

Cases of greater political development that would be exceptions to the above - for example, the Blackstone Nation, the Black Panthers, and the concept of community power - were brought about by forces external to the gang (Short 1976). Political development has occurred, if at all, not as a consequence of a beginning dialog between poor gang members and non-poor radical organizers, but as a response to structural factors that were not intended as such to radicalize the poor. These factors include economic changes in the communities to which gangs belong. federal governmental policies, particularly those concerned with municipalities and local communities, and police interference with gang activities. Thus, though certain structural changes have effected the political role of poor youths, the problem of communication and political solidarity between groups of different strata is still to be resolved.

Studies of language use may be helpful in this regard especially if we can relate them to broader social structural and political issues. In the present essay we discuss theories that bring the methods of linguistics to micro-sociological studies of speech behavior. Our task is to relate this work to the rich ethnographic literature on low income culture, and then to place this amalgam in a larger political economic context. Finally, we hope to make explicit some moral and political implications of such a project.

\section{The social structural foundations of language}

It is a curious fact that both the 'right' and the 'left' tend to perceive differences between middle class and lower class speech in terms of the linguistic inadequacy of the latter. The intellectual armament of conservatives and liberals includes social scientific notions of the 'culture of poverty', 'cultural disadvantage', and 'linguistic deprivation'. Similarly, among left-wing writers and students in both America and Europe. lack of understanding between organizers and low income youths is often attributed to the false consciousness or verbal and political backwardness of the poor.

Though widely held by educational psychologists (Bereiter and Engelmann 1966), the theory of verbal deprivation has been challenged on various grounds (Bernstein 1972a, 1972b; Labov 1972a, 1972b; Lawton 1968; Leacock 1972: McCormickPiestrup 1973). Basil Bernstein's work in particular provides a privileged site for entering this debate, because of its ambivalence concerning verbal deprivation. On the one hand Bernstein's work is used as an argument in support of the deprivation theory: on the other hand. his findings can be recast to show that this use is an abuse, and that the verbal deprivation theory is misleading.

Arguing from the disproportionate failure of black children in school as well as extensive experimental data, theorists of verbal deprivation maintain that the speech of low income groups is an inherently inferior vehicle of thought and communication. In this view, the language of ghetto children entering pre-school is regarded as a 'series of emotional cries ... not merely an underdeveloped version of standard English, but basically a nonlogical mode of expressive behavior' (Bereiter and Engelmann 1966). Though this might be an extreme position, it is 
often defended by reference to the theoretical concepts of Bernstein (McCormick-Piestrup 1973:11). With some modifications, we agree with Bernstein's objection that his concepts do not support theories of verbal deprivation.

Bernstein's concern is not language as such, but social structure and social interaction in its symbolic realizations through forms of speech. Particularly. Bernstein focuses on the socialization process of children in families differentially located in the class structure. Unlike the narrow Whorfian hypothesis of the primacy of language in determining the conceptualization and shaping of experience. Bernstein takes a Durkheimian perspective on language by emphasizing the social structuring of meanings and on their diverse but related contextual linguistic realizations' (1972a:158). He stresses not the syntactical and phonological questions, but the social relationship and moral orders that are realized through different sociolinguistic codes.

A fuller understanding of Bernstein's concepts of linguistic codes and speech variants is important for ideas we wish to develop concerning the relationships between sociolinguistics and the politics of helping. Bernstein (1964) describes two main codes of speech - the restricted code and the elaborated code. The former orients the speaker toward particularistic orders of meaning, the latter orients hım toward universalistic ones. While using a restricted code the speaker does not explicitate the general principles and operations that govern relationships between objects and persons. Instead, the speaker assumes an order of meaning that is more bound to specific contexts. Conversely, by using an elaborated code, the speaker can make explicit (or at least more explicit) the principles and operations governing his world of meanings.

The main point, says Bernstein (1972a), is that the differing speech accomplishments of children differentially located in the class structure must be understood in terms of social relationships they experience in the socialization setting of their families. In the case of a working class child the dominant relationships in the family are those that Bernstein calls 'communalized roles'. i.e. roles in which consensus between the actors is the most important property. consensus in the sense that the actors share the same cultural history, stress the similarity of their experiences, and have many common assumptions. Conversely, the social relationships of a middle class child in this family setting are characterized by individualized roles', i.e. roles that stress the difference between the actors, their experiences, their assumptions, and their points of view. Restricted speech variants have their basis in communalized roles, elaborated speech variants are rooted in individualized roles.

By relating different speech variants to different forms of social orders. Bernstein creates a framework for analyzing the speech of persons acting in different forms of social relations. Bernstein argues that the class structure. and particularly working class socialization, limits access to the kind of universalistic order of meaning that is realized in individualized role relations. Though this leads to difficulties for the working class child in handling individualized roles, Bernstein (1972a) emphasizes that on the level of grammatical and linguistic choices the working class person has access to a rich vocabulary, a highly differentiated noun phrase, and to a wide range of syntactical choices that involve the use of logical operators such as 'because', 'but', 'either', 'or', and 'only'. As Bernstein points out, however, 'if you 
cannot manage the role, you cannot produce the appropriate speech' (Bernstein $1972 \mathrm{a}, 1962$ ). In other words, 'because the code is restricted it does not mean that speakers at no time will not use elaborated speech variants. Only that the use of such variants will be infrequent in the socialization of the child in his family' (Bernstein 1972a:173). The children are not linguistically deprived. Rather, they are restricted as to contexts in which elaborated speech variants might be properly expressed - that is, contexts of individualized roles. Theorists of the verbal deprivation of lower class children have claimed Bernstein's work as part of their argument. But this is made possible only by ignoring his key concept of different orders of meaning encoded through different social structural and contextual relationships. This is a distortion of Bernstein's writings; it is an abuse.

\section{The myth of the 'nonverbal' child}

The theory of linguistic deprivation is also criticized in studies by William Labov (1972a, 1972b). Through analyses of the speech mainly of black gang members, Labov shows that nonstandard English dialects are not radically different from standard English, but on the contrary are closely related to it, involving alternative versions of the same basic rules. Despite differences in the phonological grammatical, and lexical aspects of lower class language, argues Labov, there is no indication of a logical or semantic difference between it and standard English or. in Bernstein's terms, between a restricted and an elaborated code. In addressing this problem Labov resolves ambiguities that remain in Bernstein's formulation.

One decisive advantage of Labov's studies is that he consciously varies the settings in which the experimental interactions take place. Labov is aware that the speech behavior of his subjects might change from one social situation to another. and that failure to note this could lead to the thesis of a nonverbal lower class child. Let us give two examples (Labov 1972a: $184 \mathrm{ff}$.). The first is an interview of a black child in a New York City school. The interviewer, who is white. places before the boy a block or a fire engine, saying. 'Tell me everything you can about this'. What follows is mainly characterized by silence on the part of the boy. Though such reticent, monosyllabic speech is normally taken as a proof of lack of verbal capacity of lower class children, Labov interprets it as the child's effort to defend himself in a hostile setting. as such a test might be described. Suspecting that when a child is interviewed in a sympathetic situation things might turn out differently, Labov and his associates changed the interview situation. This time a skilled black interviewer brought along a supply of potato chips, invited the child's best friend to come too, sat on the floor with the children, and introduced taboo words and subjects. What followed was a highly vivid conversation in which the 'nonverbal' lower class child disappears entirely. Instead, we have two verbally animated boys who have much to say and no difficulty in using the English language to say it.

We do not wish to overemphasize the similarities in the theoretical approaches of Bernstein and Labov, especially as Labov does not develop a social structural concept of linguistic codes, but on the contrary stresses the situational aspect of verbal behavior. However, both authors deny any difference in the linguistic competence of different social groups; instead, they agree in explaining differences 
in the overt verbal bevavior in terms of differences in the cultural or situational organization of various speech events. As Labov puts it. 'The social situation is the most powerful determinant of verbal behavior' (Labov 1972a:191). If the situation that the child confronts is asymmetrical or hostile. thereby provoking a defensive reaction, then we will not experience a verbally active child.

\section{The problem of logic and abstraction}

Though Bernstein's and Labov's work can be used against the theory of verbal deprivation, there still remains an important problem: Even allowing that language differences between different socio-economic groups reflect different cultural orders of meanings or settings, it still could be argued that the language related to certain cultural settings is characterized by lack of abstractness and logic.

Bernstein states that the grammatical structure of the restricted code supports a nonlogical way of thinking: reason and conclusion are often confounded to produce a categoric statement. Restricted speech is of low generalization. lacks differentiation, and is inconsistent. In short, restricted language limits interest in general relationships that transcend the immediate situation. thereby making discursive thinking difficult. For example. Bernstein (1972a) writes that persons speaking an elaborated code realize an order of meaning that is "less context bound" whereas speakers of a restricted code realize an order that is 'more context bound". In the case of elaborated codes the speech is freed from the social structure that evokes it and takes on an autonomy. Realizing a "universalistic order of meaning" implies that individuals have access to the grounds of their experience and can change the grounds'. On the other hand, restricted codes, being 'more tied to a local social structure', have a 'reduced potential for change in principles'. Speakers of a restricted code have great difficulties in entering into 'a refiexive relationship to the social order' that they have interiorized (Bernstein 1972a:164). Do these formulations not suggest a lack of abstraction and logic in the restricted code? Though Bernstein tries to highlight an important feature of the cultural and social order of low income groups, he remains ambiguous concerning abstraction, logic. reflexiveness, and the potential for 'change in principles'.

In order to clarify the problem of abstraction and logic in different speech codes the ideas and examples of yet another sociolinguist, Eleanor Leacock, are helpful. Leacock (1972) calls the sympodium of abstract and concrete speech a false dichotomy'. Reviewing the historical and ideological roots of this dichotomy, she sees it as an oversimplified version of the Whorfian hypothesis, and expression of ethnocentrism, and a consequence of the establishment of standard English as a status criterion. 'Strictly speaking', says Leacock. 'there is no such thing as concrete speech or language' $(1972: 126)$. Every language by its very nature is abstract because it is essentially a system of rules. Every word we use abstracts relational properties from the totality of 'concrete' given entities. As Lenneberg, cited by Leacock, puts it:

In all languages of the world, words label a set of rational principles instead of being labels of specific objects. Knowing a word is never a simple association between an object and an acoustic pattern. but the successful operation of those principles. or application of those rules, that lead to using the word 'table' or 'house' .... (Lenneberg 1464:(6+1) 
If there is a difference in styles of speech of different groups, it does not lie in the abstractness of their language, "but in differences in the areas wherein conceptualization is more consciously developed, and in the ways in which concepts are expressed or elaborated upon' (Leacock 1972:127). As an example, Leacock discusses the use of metaphors noted to be a common characteristic of black speech communities, and of black lower class speech in particular. For instance, there is a wide range of metaphorical expressions concerning difficulties of black people in the world of employment: 'They clip your wings and tell you to fly'. 'You take the starch out of a shirt and it doesn't iron too good'. 'You have to learn to step between the raindrops', and so on (1972:129). Far from being merely 'concrete', however, metaphors are very abstract forms of symbolization. By using a metaphor, the speaker abstracts qualities perceived as similar from dissimilar phenomena. For example. 'They clip your wings and tell you to fly' does not refer to birds only, but also to the black worker who has to accomplish the impossible: He has no employment opportunities but is expected to hold a steady job. In the metaphor, the relevant features of a situation are stated as an analogy. Metaphors are logically economical, eliminating the need for an overload of qualifying terms (Brown 1977). Referring to Kenneth Burke. Leacock makes us aware that the features of metaphoric symbolization are inseparably part of any scientific inquiry. which itself proceeds metaphorically 'through the processes of oversimplication, abstraction. and analogical extension' (1972:129). In short, the analytical value of the dichotomy between 'abstract' and 'concrete' speech codes is doubtful: it solves no problems and conceals more than it reveals.

If we cannot characterize the vernacular of low-income groups as less abstract compared with an elaborated code, what then distinguishes the restricted code? To answer this question we turn to a provocative analysis by Labov of two interviews focusing on matters of belief (1972a). One interview is about God and life after death, the other about witcheraft. Whereas the latter is conducted with an adult upper middle class, college educated black, the former takes place with Larry, one of the roughest members of a black gang: he is 15 years old and has troubles in school.

Comparing both interviews. Labov (1972a:194) notes two different kinds of speech regarding their lexical and grammatical properties. The middle class speaker uses forms of language close to the elaborate code described by Bernstein. $\mathrm{He}$ employs longer sentences, more subordinate clauses, more evaluative statements, a more learned vocabularly, and he takes a rather 'individualized' role. Conversely, the gang member uses speech that is almost paradigmatic of nonstandard Negro English. There is the characteristic negative inversion, negative concord, invariant be, it instead of there, as well as a lack of evaluative statements such as those used by the middle class adult.

Given these different forms of language, is there any indication of a difference in the logical forms of the two answers? Can we make any assertion that one of the two ways of speech implies a superior logic? Labov analyzes the logical structure of both answers to show explicitly that Larry, the gang member, presents a complex set of interdependent propositions organized within the rules of logic. Even if some of his propositions are unstated or 'implicit', thus indicating the use of a restricted code, when challenged by the interviewer invoking the rules of logic. Larry gives 
us an account of the underlying relationships that shows a thoroughly logical reasoning, even though some of the propositions remain unstated, that is, the 'if' clauses are lacking. But there is no doubt that Larry argues on the grounds of these clauses, even though he does not render them explicit.

Turning to the account of the middle class speaker. Labov does not find a superior use of logic. Indeed, by reducing the arguments of the speaker to their basic content, Labov discovers one not very exciting statement: I believe in witchcraft. By bracketing the redundant or contradictory information. Labov shows that this middle class form of speech is not more rational, more logical, or more intelligent. It is merely verbose, educated.

In short, standard and nonstandard English, or restricted and elaborated codes and speech variants, are all 'abstract'. Further, there is no reason to presuppose a deep (if any at all) logical difference between different speech codes and their variants. There might be some aspects of the elaborated code or formal middle class speech that facilitate the acquisition of knowledge and verbal problem solving. but this question remains open (Labov 1979:138). And even to address it we would have to distinguish that aspect of speech which is functional for learning, and that which is functional for acquiring and demonstrating middle class status or relating easily to middle class teachers. For the time being. educational practice and especially theories of verbal deprivation, are confounding both aspects.

\section{A sociological reconsideration of Bernstein's concepts}

In light of the foregoing it seems appropriate to reconsider Bernstein's formulations. If there is no deep difference in the logical or abstract character of different speech codes, Bernstein's notions become problematic. This can be shown by extending his assumptions even further; by reaffirming his Durkheimian perspective on language we can show its limits. Central to Bernstein's view of middle and lower class cultures are Durkheim's concepts of organic and mechanical solidarity (Durkheim 1933). These concepts lie behind Bernstein`s models of elaborated and restricted codes, explicitness, and implicitness, universalistic and particularistic orders of meaning (cf. Lawton 1968). In his acceptance of these Durkheimian concepts lies the problematic character of Bernstein's formulations: The concepts being too imprecise for Bernstein's task, he is confronted with the same problems that led Durkheim to abandom the dichotomy in his later writings.

Before suggesting an alternative sociological model. we should note the empirical features to which Bernstein refers. In this, we will confine our discussion to problems of lower class culture. The most prominent feature of this culture is suggested by Bernstein's notion of 'context-bound' and 'implicitness', or what, in early studies, William F. Whyte called the 'hierarchy of personal relations' or 'systems of particularistic loyalties' (Whyte 1955). These terms describe three distinct features of low income or slum areas. The first feature of lower class life is the emphasis on primary group relations. Living in settings that expose them to unpredictable changes, faced with poor public services, crowded apartments, and so on. slum inhabitants rely primarily on groups they know and can trust - the family and the gang (Cohen 1955: Firth 1956; Mays 1969: Miller 1958: Parker 1974: Siberstein 
1969: Thrasher 1963: Willmott 1962; Young 1969). Second, such primary relationships are based on the principle of reciprocal assistance. This principle consists, on the one hand, in accepting and using the resources of friends without feeling guilty or ashamed and. on the other hand, in feeling commitment to help one's friends, to give them back some version of what one has received (Cohen 1955: Silberstein 1969: Whyte 1955). A third feature of lower class life might be called the personalization of social relations. Being dependent on the help of others, the lower class member tries to establish very personal and intimate relationships between himself and the persons he needs (Silberstein 1969: Spinley 1953). 'Open criticism seldom is based on general mores but measures each individual according to the premises and commitments laid down in history. What might be praiseworthy behavior for one individual can be shameful to another' (Suttles 1968:79).

Now. instead of conceptualizing these features of lower class life solely in terms of vague notions characteristic of nineteenth century thought, we can draw upon the large corpus of empirical studies of such lower class attributes as particularistic loyalties, affectively, and so on. In other words, we must supply the sociological analysis of actual lower class behavior that Bernstein omits. Such an analysis must draw on the close observations of ongoing situations and be precisely formulated so that its propositions are falsifiable by further empirical observation. One approach that might meet these criteria is the concept and theory of norm and sanction as developed by Geiger (1964), Popitz $(1961,1967,1968)$ and his former students Blankenburg (1969, 1970). Spittler $(1967,1970)$. Treiber $(1973 \mathrm{a}, 1973 \mathrm{~b})$ and von Trotha (1974).

According to Popitz, the concept norm refers to regularities of behavior (Verhaltensregelmaessigkeiten) that are compulsory for an actor. One can recognize norms by the reaction that follows when an actor regularly violates them. 'Deviance' is followed by sanctions, that is. by reactions that express disapproval of the conduct in question. Like every social construct, norms are abstractions of realities. Norms idealize relationships between actors in specific ways: that is, they standardize definitions of situations, behavior in these situations. and the actors to whom they are addressed. Similarly, sanctions standardize reactions toward norm violations, i.e. toward deviant behavior.

Using the concepts of norm and sanction in a study on the conditions of socialization (Vergesellachaftungsbedingungen) in slum areas, von Trotha (1974) reformulated much of the literature on lower class neighborhoods. His main finding was that the concepts of 'particularistic loyalties', 'systems of personal relationships', or the greater amount of 'spontaneity' in lower class relations. can be understood as analytical descriptions of a specific kind of normative order. That is, studies of lower class areas, and in particular the world of gangs, in effect describe settings in which:

1. The kind and degree of standardization of behavior called normative as defined above, is not much found in the ordering of social relations between lower class members.

2. To the extent that it is found, its enforcement through sanctions is highly inconsistent.

Typically, in lower class settings great scope is left to the individual to interpret the situation. Instead of finding fixed intersubjective standards to guide them, lower class persons must incessantly focus on the cues and clues of specific situations to 
discern, or to invent ad hoc, the meanings and actions that might be appropriate. The Procrustean bed of that kind of idealization of reality we call norms is often not given - at least not in the degree as in higher class settings. In short, though the discretionary power of the lower class actor is reduced with reference to the larger political economy, it is increased and, indeed, required with reference to his specific situations. Much more than the upper or middle class actor. members of the lower class must decide what game is being played and how they are to play it.

The first consequence of this clarification is that we can understand more precisely what Bernstein may intend by his concept 'communalized roles'. These are 'roles' for which the standardization of behavior has not been consolidated (verfestigt) into norms. And this phenomenon is strikingly inconsistent with a picture of lower class relationships as one of 'mechanical solidarity' and its corresponding sociolinguistic models. This reformulation of 'communalized roles' also enables us to redefine the problems of abstraction, and to render problematic Bernstein's propositions not only from a linguistic point of view but also from a social structural perspective.

\section{A redefinition of abstraction}

We have shown that on the cognitive level there is no difference in the property of 'abstraction' of different speech codes between standard English and a vernacular. The same can be said for all forms of social relationships and for all forms of socialization. As Simmel argued so convincingly in his 'Exkurs ueber das Problem: Wie ist Gesellschaft moeglich?" (1968), society has to be understood as a relation between socially generalized persons. At no time and in no place do we see the other in his total individuality, as an individual as such. We always see the other as being something more general, as an undergraduate or a professor, as a worker or a professional, as a deviant or a respectable citizen. We 'abstract' from the singularity of individual existence and standardize its features by creating intersubjectively recognizable categories. We typify; and our typifying the acting. feeling, thinking - the very 'nature' of individuals - is a precondition of the possibility of society. The abstract property of social relations is a basic principle of the construction of social reality, a daily accomplishment by all members out of their intersubjective existence.

Viewed in terms of this phenomenological insight, the concept of abstraction becomes ambiguous as a means of discriminating between different kinds of social relations. Rather than using this notion to describe the social structure of lower class areas, instead we look for different ways, or forms as Simmel would say, through which social relations are established. Thus, in this perspective, the dichotomy between individualized and communalized roles appears to describe a form. differentiated by class, for standardizing conduct. Does this not re-introduce the concept of abstraction? Certainly it does. But it does so in a way that redefines the problem. Specifically, instead of using the word abstraction' we can say, more precisely, that the actors take into account a different set of circumstances in constituting their situations. In this formulation the properties of communalized and individualized roles do not appear as ordered in a hierarchy of 'abstraction'. Instead they are different modes of responding to the universal challenge to establish 
the 'abstract' relationships basic to social existence. All humans share the burden of living their social beings through abstract realities, but they can use different forms to construct these abstractions. Generally speaking, in abstracting or constructing his immediate reality. the lower class person considers a wider range of imponderables, and can take less for granted, than does the middle class actor. Thus Bernstein's original notion of 'abstraction' is completely transvalued.

\section{The problem of flexibility and social change}

In one of the articles we discussed Labov asks the question: 'Is the "elaborated" code of Bernstein really so "flexible" . . a as some psychologists believe?' (Labov 1972a : 192). According to Bernstein the answer seems to be yes. For example, we cited Bernstein saying that in the case of elaborated codes speech . . . takes on an autonomy' in that the individuals using an elaborated code 'have access to the grounds of their experience and can change the grounds'. On the other hand, speakers of a restricted code have a 'reduced potential for change in principles'. Yet, in dicussing the problem of abstraction and the logic of different speech codes, we saw no linguistic evidence that verifies these propositions. At the same time, we also had to reformulate Bernstein's Durkheimian concept of social structure in order to resolve problems on the linguistic level. In short, the notion of the unflexibility of a restricted code is grounded in the assumption of an unflexible lower class social order. We now want to extend the concepts of norm and sanction to argue further that the so-called inflexibility of lower class persons is incorrect.

There are two aspects of the 'culture of poverty' - or more accurately, the culture of the oppressed - that are likely to produce what on the surface. but only on the surface, appears as 'restricted' or 'inflexible' speech and conduct. As noted above, these aspects are the reduction of the normative standardization of behavior, and the reduction of sanctioning. For example, one dominant feature of lower class groups is that the relation between wife and husband may easily be revoked. The breach of the conjugal bond in such settings is not a last resort but an ordinary experience. Instead of making it a normative obligation to stay together the wife's attitude to men might be described by the expression 'I'll let him love me (and I'll love him) until he doesn't act right. Then I'll kick him out'. The attitude of the man is 'Love 'em and leave 'em'. The man is a guest, often only a tolerated guest, especially when he is broke (Drake and Cayton 1962; Bartels 1975). In other words the reduced normative standardization of conjugal behavior is expressed in the ease by which that relationship may be broken.

A second feature of lower class life is that children often are without adult supervision, the mother being overburdened with the necessities of the household, or out of the house entirely, working in a factory or an affluent home. Thus no one is there to impose sanctions when deviant acts are being committed by lower class children. Violation of parental norms is less recognized and the child has, so to speak, a temporary immunity from punishments.

These examples (and others in von Trotha 1974) suggest that lower class orders are ones in which people have great flexibility in defining their immediate relationships and actions. Tbough they have scant influence on official definitions of deviance, they do have ample existential possibilities for violating such definitions. 
Moreover, such flexibility appears to be a rational coping device for individuals who have little control over actions by members of other classes that directly affect their lives. For example, for those 'last to be hired, first to be fired', unemployment is an everyday possibility, integral to the expectations of slum dwellers and especially of the young. Moreover, to find a job does not mean that one will be able to keep it, or even go to work tomorrow. One imponderable is health. White collar employees can work despite a broken leg. But a hod carrier can not. And the hod carrier is more likely to be exposed to unsafe and unsanitary conditions of work, transportation, and domestic life. Thus going to work and being in good health do not become taken for granted conditions for low income people. Instead, they are problematic and uncertain.

There thus seems to be an inverse relationship between the degree of control over one's conditions of existence and the degree of control over one's existential actions. The middle or upper class person has more control over the conditions or is less effected by changes in them. But he buys this security by acting in accordance with normatively standardized and routinely sanctioned patterns of behavior. The lower class person, by contrast, is most vulnerable to changes in his conditions, but - just because of this - he displays those 'existential' qualities of spontaneity, daring, physical courage, loyalty to peers, resistance to authority, and fatalism that Miller, Whyte, and many others have noted as characteristic of low income cultures, and especially of urban, delinquent groups.

Seen in this perspective the property of flexibility becomes almost a functional prerequisite of a social order in which the individual actor in his daily life is exposed to changes that affect the essential conditions of his wellbeing but over which he has little or no control. It is the lower class person who is struck most by economic crises, by illness, by war. And it is he or she who has to 'adapt'. Thus the Durkheimian concept of a tightly knit social structure in which the individual is completely enclosed, misunderstands the nature of the social structure of lower class neighborhoods and particularly of gangs, and grossly underestimates the effects of more general social changes on the lives of lower class members. Sociologists holding this view have been preoccupied with observing interactions within peer groups, without noting the ease by which, for instance, gangs dissolve (Kobrin and Yablonsky 1967) and without considering the forces and factors external to gangs. Instead, if one looks at such structural pressures the whole picture changes, and we see why in some situations we experience an almost monosyllabic speaker whereas in others we find a speaker who is a very effective narrator, reasoner, and debater (Labov 1972: 193).

Let us summarize: Arguing from a linguistic point of view, we saw that there is no indication of a lack of logic and abstraction as such in lower class speech or in the Black vernacular. Further, having rendered problematic some of Bernstein's notions, we took his Durkheimian concept seriously and looked for the social structural conditions that produce different kinds of speech. We saw that the ambiguities in Bernstein's ideas arise from his misconceptions about the social structure of lower class relationships. Let us now return to our original question: What have these considerations to do with the difficulties that middle class organizers have in communicating with lower class persons in general and with gang members in particular? 


\section{The problem of communication}

Reasoning from our observations of lower class speech, we can imagine manifold situations in which we as middle class persons cannot produce the right sentence in the right way because we cannot accomplish the appropriate role. This in fact is precisely what happens when 'intellectuals' try to talk with 'poor people'. Middle class persons - conservative. liberal. and radical alike - have systematically failed to discover the kinds of role relations necessary for communicating with adults or children who realize different orders of meaning. Only through such roles could middle class persons become able to produce the adequate speech. But rather than confronting this difficulty and establishing new role relationships with the poor. middle class experts or organizers have tended to rationalize their inability by constructing theories of 'linguistic deficiency' and programs of 'compensatory education', or by simply giving up on the poor as 'backward' or 'authoritarian".

But the problem of communication is much more challenging than such concepts as lower class authoritarianism, lack of education. or even false consciousness suggest. What is at issue here is not the limitations inherent in lower class culture as such, but rather a profound conflict between members of different cultural and social structural orders. between lower class individuals and upper and middle class persons who presume to help them. One problem of the role of the intellectual in reformist or revolutionary practice is not that the intellectual is an intellectual. but that he or she is middle class. Such a person is confronted with an alien system of meaning, realized in alien ways of ordering social relations. expressed in alien forms of speech.

In terms of these considerations, the questions. What is education? and Who is to be educated?. become crucial. If language deprivation is a myth. if there is no indication of a lack of logic encoded in lower class speech. if low income persons are not inflexible conformists, then the questions arise: Were the concepts of education or politicization grounded in what might be called cultural imperialism? Have we regarded middle class styles of life and speech as the criteria for being accepted as an educated or politically aware person? Did Bernstein avoid the radical consequence of his concept of different orders of meaning? Did we incorrectly label the 'passivity' of street corner groups in politics either as working class authoritarianism or as false consciousness? and did this simply misconstrue what is going on, by misunderstanding either the interests of the street corner groups or the significance of these interests for their daily lives? For instance, when an organizer talks about the deprivation of the gang member, he gets a very straightforward answer. But this answer, contrary to any simple concept of lower class conservatism. shows a profound disrespect for the present system of power even while reflecting its materialist values.

Concepts of verbal deprivation or false consciousness, then, are correct: but they are correct mainly when applied to middle class experts or activists seeking to help the poor. Applied to low income people and gang members as they relate to education in their own words and worlds, these ideas become misconceptions. Of course, we are not saying there is no lower class authoritarianism. There is authoritarianism and even more, there is deprivation. But we want to emphasize the following: Before we develop concepts or programs to educate or to politicize 
lower class members, we have to realize that we are involved in a conflict between different social orders. And in accepting this we must recognize that the problem of communication can only be resolved if we become in a very radical sense participants of the ongoing communication process. That is. we ourselves have to be as much educated and politicized as the lower class members to whom our speech acts and our programs are addressed. We must train ourselves to take the viewpoint of the other, to establish a communication process that by its very nature is dialogal and, more, is dialectical as well. We must make ourselves vulnerable, to take psychic and cultural risks just as we ask the same risk of the persons we presume to help. We have to present our truths as witnesses and not merely represent them as bureaucratic or as radical technicians. To do all this would be to make our theories practical and our speech acts of political and moral courage. It would liberate us from unreflective theorizing even while engaging us in emancipating practice.

Correspondence to: Trutz 'on Trotha. Institute für Soziologie, Universitat Hannover. Hanomagstrasse 8. D-3000 Hannover 91. West Germany; Richard Harvey Brown, Washington Institute for Social Research, Department of Sociology. University of Maryland. College Park MD. 207+2 USA.

\section{References}

Bartels, S. Der matrfokale Haushalt als gesellschaftliches Massenphaenomen. Ph. D. Dissertation, Universitaet Freiburg. Freiburg/Brsg. 1975.

Bereiter. C. \& Engelmann. S. Teaching Disadeantaged Children in the Preschool. Prentice Hall. Englewood Cliffs, N.J. 1966

Bernsteın, B. 'Some Sociological Determinants of Perception: An Enquiry into Subcultural Differences'. British Journal of Sociology'. Vol. 9 (1958). pp. 159-174.

Bernstein, B. 'A Public Language: Some Sociological Implications of a Linguistic Form British Journal of Sociology, Vol. 10 (1959). pp. 311-326.

Bernstein. B. 'Language and Social Class'. Bruish Journal of Soctology'. Vol. 11 (1960). pp. 271-276.

Bernstein, B. 'Elaborated and Restricted Codes: Their Origins and Some Consequences'. In J. J. Gumberz \& D. Humes (Eds.). The Elhnography of Communication. American Anthropologist. Special Publication 66. No. 6. Part 2. 1964. pp. 55-69

Bernstein. B. 'A Socio-Linguistic Approach to Social Learning'. in J Gould (Ed.), Penguin Survey of the Social Sctences, Penguin Books. Harmondsworth 1965. pp. 1+1-168.

Bernstein, B. 'Social Class, Language, and Socialization', in P. P. Giglioli (Ed.). Language and Soctal Context, Penguin Books. Harmondsworth 1972a. pp. 157-178.

Bernstein. B. 'A Critique of the Concept of Compensatory Education'. in C. B. Cazden. V' P. John \& D. Hymes (Eds.). Functions of Language in the Classroom. Columbia Unisersity Teachers College Press. New York 1972b. pp. 135-151.

Blankenburg. E. 'Die Selektivitaet rechtlicher Sanktionen. Ene empirische Untersuchung von Landendiebstaehlen”. in Koelner Zetischrift fuer Sociologie und Sozialpsychologie. Vol. $21(1969)$, pp. 805-829.

Blankenburg. E. 'Das Recht als Kategorie sozialer Verhaltensregelmaessigkeiten'. in R Lautmann. W. Maihofer \& H. Schelsky (Eds.). Die Funktion des Rechls in der modernen Gosselschaft, Jahrbuch fuer Rechts-soziologe and Rechtstheorie. Vol. I. Bertelimann Universitaetsverlag. Bielefeld 1970. pp. 227-234

Brown R. H. A Poetic for Sociology: Toward a Logic of Discovery for the Human Sciences. Cambridge University Press, London and New York 1977

Cohen, A. K. Delmquen Boys, The Free Press. Glencoc, Ill. 1955. 
Drake, St. C. \& Cayton, H. R. Black Metropolis, Harper \& Row, New York-Evanston 1962.

Durkheim. E. The Division of Labor in Society. Macmillan. New York 1933.

Firth. R. Two Studies of Kinship in London. Athlone Press. London 1956.

Geiger. T. Vorstudien zu einer Soziologie des Rechts. Luchterhand. Ncuwied 1964.

Habermas. J. 'Toward a Theory of Communicative Competence', in H P. Dreitzel (Ed.), Recent Sociology', No. 2. Macmillan, New York 1970

Kobrin, S. 'Sociological Aspects of the Development of a Street Corner Group'. American Journal of Sociology. Vol. 31 (1961). pp. 685-702.

Krisberg, B. A. The Gang and the Community, School of Criminology. UC Berkeley, Berkeley. Ca.. December 1972. mimeographed.

Labov. W. 'The Logic of Nonstandard English', in P. P. Giglioli (Ed. ). Language and Social Context. Penguin Books. Harmondsworth 1972a, pp. 179-215.

Labov, W. 'The Study of Language in its Social Context', in P. P. Giglioli (Ed.), Language and Social Context. Penguin Books. Harmondsworth 1972b, pp. 283-307.

Lawton, D. Social Class, Language, and Education, Routledge \& Kegan Paul, London 1968; Penguin Books, Harmondsworth 1972b, pp. 283-307.

Leacock. E. B. 'Abstract Versus Concrete Speech: A False Dichotomy', in C. B. Cazden. V. P. John \& D. Humes (Eds.). Funcrions of Language in the Classroom. Columbia University Teachers College Press, New York 1972, pp. 111-134

Lenneberg, E. H. 'On Explaining Language', Science, Vol. 164 (1969), pp. 635-643.

McCormick-Piestrup, A. Black Dialect Interference and Accommodation of Reading Instruction. Monographs of the Language Behavior Research Laboratory. UC Berkeley, No. 4, Berkeley 1973.

Mays. J. B. Growing Up in the City. Liverpool University Press. Liverpool 1964.

Miller, W. B. 'Lower Class Culture as a Generating Milieu of Gang Delinquency'. Journal of Social Issues, Vol. 3 (1958), pp. 5-19

Parker, H. J. View from the Boys. David \& Charles, New Abbott 1974.

Popitz, H. 'Sociale Normen'. European Journal of Sociology', Vol. 11 (1961), pp. 185-198.

Popitz. H. Der Begriff der socialen Rolle als Element der soziologischen Theorie. J. C. B Mohr. Tubingen 1967.

Popitz, H. Uber die Praeventiwirkung des Nichtwissens, J. C. B. Mohr, Tubingen 1968.

Short, J. F. Jr. 'Gangs, Politics, and the Social Order', in J. F. Short, Jr.. (Ed.). Delinquency, Crime and Society'. University of Chicago Press, Chicago 1976. pp. 129-163.

Silberstein, P. 'Favela Living: Personal Solutions to Larger Problems', America Latına, Vol. 12 (1969). pp. 183-200.

Simmel, G. Soziologie. Duncker \& Humblot, Berlin 1968.

Simmel. G. On Individuality and Social Forms, D. N. Levine (Ed.). University of Chicago Press, Chicago 1971

Spergel, I. Politics, Policies, and the Youth Gang, School of Social Service Administration. University of Chicago 1969. mimeographed.

Spinley, B. M. The Deprived and the Privileged, Routledge \& Kegan Paul, London 1953.

Spittler. G. Norm und Sanktion. Walter Verlag. Olten 1967

Spittler, G. 'Probleme bie der Durchsetzung sozialer Normen'. in R. Lautmann, W. Maihofer \& H. Schelsky (Eds.), Die Funktion des Rechts in der modemen Gesellschaft. Jahrbuch fuer Rechtssoziologie und Rechtstheorie, Vol. 1. Bertelsmann Universitaetsverlag. Bielefeld 1970, pp. 205-225.

Stanley. M. The Technological Conscience. Survival and Dignity in an Age of Expertise. Free Press, New York 1978.

Suttles, G. D. The Social Order of the Slum. University of Chicago Press, Chicago 1968.

Thrasher, P. M. The Gang. University of Chicago Press, Chicago 1963.

Treiber, H. Wir man Soldaten macht, Bertelmann Universitaetsverlag. Duesseldorf 1973a

Treiber, H. 'Entlastungseffekte des Dunkelfeldes. Anmerkungen zu einer Dunkelzifferbefragung', in Kriminologisches Journal, Vol. 2 (1973b), pp. 97-115.

Trotha. T. von. Jugendliche Bandendelingquez, Enke. Stuttgart 1974.

Weinstein. D. \& Weinstein, M. A. 'An Existential Analysis of Social Control: A Neglected Dimension. Paper presented to the American Sociological Association Meetings, New York 1976 
White, W. F. Street Corner Society, University of Chicago Press. Chicago 1955.

Willmot. P. Adolescent Boys of East London. Penguin Books. Harmondsworth 1969.

Yablonsky. L. The Violent Gang. Penguin Books. Harmondsworth 1967.

Young, M. \& Willmott, P. Family and Kinship in East London. Penguin Books. Harmondsworth 1962 . 